\title{
Faktor risiko yang berhubungan dengan kejadian berat badan lahir rendah pada neonatus yang dirawat di RSUP Prof. Dr. R. D. Kandou periode Januari 2015-Juli 2016
}

\author{
${ }^{1}$ Enny Susilowati \\ ${ }^{2}$ Rocky Wilar \\ ${ }^{2}$ Praevilia Salendu
}

\author{
${ }^{1}$ Kandidat Skripsi Fakultas Kedokteran Universitas Sam Ratulangi Manado \\ ${ }^{2}$ Bagian Ilmu Kesehatan Anak Fakultas Kedokteran Universitas Sam Ratulangi Manado \\ Email: Enny_lycy01@ rocketmail.com
}

\begin{abstract}
Infants with low birth weight is a complex issue and has contribution in the high rate of morbidity and mortality, disability, various disorders or inhibition of growth and cognitive development as well as other chronic diseases. This study was aimed to obtain the risk factors associated with low birth weight of neonates at Prof. Dr. R. D. Kandou Hospital in Manado from January 2015 to July 2016. This was a descriptive retrospective study with a field survey method. Samples were patients diagnosed as low birth weight neonatus treated at Department of Pediatrics of Prof Dr. R. D. Kandou Hospital Manado from January 2015 to July 2016. The results showed that based on maternal risk factors (age, parity, maternal infection, premature, multiple pregnancy and history of low birth weight neonates), fetal and placental (congenital abnormalities) factors, and environmental factors (smoker and drunk), the most frequent risk factor was prematurity. Conclusion: In this study, the most frequent risk factor of low birth weight infant was prematurity
\end{abstract}

Keywords: low birth weight, rick factors, neonate

\begin{abstract}
Abstrak: Bayi dengan berat badan lahir rendah (BBLR) merupakan masalah yang sangat kompleks dan memberikan kontribusi dalam hal tingginya angka morbiditas dan mortalitas, kecacatan, gangguan atau terhambatnya pertumbuhan dan perkembangan kognitif, serta penyakit kronis dikemudian hari. Penelitian ini bertujuan untuk mengetahui faktor risiko yang behubungan dengan kejadian BBLR pada neonatus yang dirawat di RSUP Prof. Dr. R. D. Kandou Manado periode Januari 2015-Juli 2016. Jenis penelitian ialah deskriptif retrospektif dengan metode survei lapangan. Sampel penelitian ialah pasien neonatus dengan BBLR yang dirawat di Bagian Ilmu Kesehatan Anak RSUP Prof. Dr. R. D. Kandou Manado pada bulan Januari 2015- Juli 2016. Hasil penelitian memperlihatkan berdasarkan faktor risiko ibu (usia, paritas, infeksi, kelahiran prematuritas, kehamilan ganda, dan riwayat BBLR sebelumnya), janin dan plasenta (kelainan bawaan), dan lingkungan (rokok dan akohol) didapatkan faktor risiko tersering ialah prematuritas. Simpulan: Dalam studi ini, faktor risiko tersering yang berhubungan dengan kejadian BBLR ialah prematuritas.
\end{abstract}

Kata kunci: BBLR, faktor risiko, neonatus

Angka kematian (AKB) merupakan indikator pertama dalam menentukan derajat kesehatan anak. Selain itu, angka kematian bayi juga merupakan cerminan dari status kesehatan masyarakat. Sebagian besar penyebab kematian bayi dan balita adalah masalah yang terjadi pada bayi yang baru lahir/neonatal (usia 0-28 hari). Masalah neonatal ini meliputi asfiksia (kesulitan bernapas saat lahir), bayi berat badan lahir rendah (BBLR) dan infeksi. ${ }^{1}$

Bayi dengan berat badan lahir rendah 
(BBLR) merupakan masalah yang sangat kompleks dan memberikan kontribusi berbagai hasil kesehatan yang buruk karena tidak hanya menyebabkan tingginya angka morbiditas dan mortalitas, tetapi dapat juga menyebabkan kecacatan, gangguan, atau menghambat pertumbuhan dan perkembangan kognitif, dan penyakit kronis dikemudian hari. ${ }^{2}$

Berdasarkan studi epidemiologi, bayi dengan BBLR mempunyai resiko kematian 20 kali lipat lebih besar dibandingkan dengan bayi yang lahir dengan berat badan normal. ${ }^{3}$ Pada tahun 2012, World Health Organization (WHO) ${ }^{4}$ melaporkan kejadian BBLR di dunia rentang tahun 2005-2010 adalah sebesar 15\%. Di South-East Asia angka kejadian BBLR mencapai 24\% dan yang tertinggi ada pada negara India dengan persentase $28 \%$.

Di Indonesia, menurut hasil Riset Kesehatan Daerah (Rikesdas) tahun 2013 menyatakan bahwa persentase BBLR sebesar 10,2\%. Persentase BBLR tertinggi terdapat di Provinsi Sulawesi Tengah $(16,8 \%)$ dan terendah di Sumatera Utara $(7,2 \%) .5,6$

Prevalensi bayi dengan BBLR di Sulawesi Utara pada tahun 2013 sebanyak 512 jiwa dengan angka kelahiran bayi sebanyak 40964 jiwa. $^{7}$ Hasil survei yang penulis dapatkan dari data register persalinan di RSUP Prof. Dr. R. D. Kandou Manado selama periode bulan Januari sampai dengan Desember 2013 dari jumlah bayi yang baru lahir didapatkan 421 bayi yang meninggal dengan penyebab kematian BBLR sebesar $209(49,64 \%){ }^{8}$

Faktor risiko yang memengaruhi terhadap kejadian BBLR antara lain ialah karakteristik sosio-demografi ibu (usia $<20$ tahun dan $>34$ tahun, ras kulit hitam, status sosial ekonomi kurang, status perkawinan tidak sah, tingkat pendidikan rendah). Risiko medis ibu sebelum hamil juga berperan terhadap kejadian BBLR (paritas, berat badan dan tinggi badan, pernah melahirkan neonatus dengan BBLR, jarak kelahiran). Status kesehatan reproduksi ibu berisiko terhadap BBLR (status gizi ibu, infeksi dan penyakit selama kehamilan, riwayat kehamilan dan komplikasi kehamilan). Status pelayanan antenatal (frekuensi dan kualitas pelayanan antenatal, tenaga kesehatan tempat periksa hamil, umur kandungan saat pertama kali pemeriksaan kehamilan) juga dapat beresiko unntuk melahirkan BBLR. ${ }^{9}$

Berdasarkan masalah-masalah yang sudah dijelaskan maka penulis merasa perlu mengadakan penelitian untuk mengetahui faktor-faktor risiko yang berhubungan dengan kejadian BBLR di RSUP. Prof. Dr. R. D. Kandou Manado.

\section{METODE PENELITIAN}

Jenis penelitian ini ialah desktiptif retrospektif. Penelitian dilaksanakan di Bagian Ilmu Kesehatan Anak dan Bagian Rekam Medik RSUP Prof. Dr. R. D. Kandou Manado.

Penelitian ini menggunakan rekam medik sebagai data sekunder dengan subjek penelitian ialah data pasien neonatus Neonatus dengan diagnosis BBLR yang dirawat di Bagian Ilmu Kesehatan Anak RSUP Prof. Dr. R. D. Kandou Manado pada bulan Januari 2015-Juli 2016. Kriteria ekslusi ialah data dari neonatus dan ibu yang tidak lengkap.

\section{HASIL PENELITIAN}

Distribusi neonatus dengan BBLR berdasarkan tahun memperlihatkan pada tahun 2015 terdapat 42 kasus BBLR pada neonatus $(68 \%)$ dan tahun 2016 terdapat 20 kasus (32\%). Jumlah keseluruhan neonatus dengan BBLR yang dirawat di RSUP Prof Dr. R. D Kandau Manado periode Januari 2015-Juli 2016 ialah 62 kasus (100\%) (Tabel 1).

Tabel 1. Distribusi BBLR berdasarkan tahun

\begin{tabular}{ccc}
\hline Tahun & Jumlah & \% \\
\hline 2015 & 42 & 68 \\
$2016($ Juli $)$ & 20 & 32 \\
Total & 62 & 100 \\
\hline
\end{tabular}

Distribusi neonatus dengan BBLR berdasarkan jenis kelamin memperlihatkan untuk laki-laki terdapat 40 kasus $(65 \%)$ sedangkan pada perempuan terdapat 22 
kasus $(35 \%)$ (Tabel 2).

Tabel 2. Distribusi BBLR berdasarkan jenis kelamin

\begin{tabular}{ccc}
\hline Tahun & Jumlah & \% \\
\hline Laki-laki & 40 & 65 \\
Perempuan & 22 & 35 \\
Total & 62 & 100 \\
\hline
\end{tabular}

Tabel 3 memperlihatkan bahwa berdasarkan kelompok usia ibu yang paling banyak melahirkan neonatus dengan BBLR ialah kelompok usia 20-35 tahun dengan jumlah 37 kasus (60\%). Kelompok yang paling sedikit terdapat pada keompok usia $<20$ tahun sejumlah 12 kasus (19\%) dan kelompok usia >35 tahun yaitu 13 kasus $(21 \%)$.

Tabel 3. Distribusi frekuensi kejadian BBLR berdasarkan usia ibu

\begin{tabular}{ccc}
\hline Usia ibu & Jumlah & \% \\
\hline$<20$ Tahun & 12 & 19 \\
20-35 Tahun & 37 & 60 \\
>35 Tahun & 13 & 21 \\
Total & 62 & 100 \\
\hline
\end{tabular}

Distribusi kejadian BBLR paling banyak pada ibu yang memiliki 1 anak dengan jumlah 30 kasus (48\%). Untuk yang memiliki jumlah anak 2 dan 3 masingmasing sebanyak 14 kasus (23\%) sedangkan pada jumlah anak 4 sebanyak 3 kasus (5\%). Angka kejadian BBLR paling sedikit pada ibu dengan jumlah anak 5 sebanyak 1 kasus (2\%) (Tabel 4).

Tabel 4. Distribusi frekuensi kejadian BBLR berdasarkan jumlah anak (paritas)

\begin{tabular}{ccc}
\hline Jumlah anak & Jumlah & \% \\
\hline 1 & 30 & 48 \\
2 & 14 & 23 \\
3 & 14 & 23 \\
4 & 3 & 5 \\
5 & 1 & 2 \\
Total & 62 & 100 \\
\hline
\end{tabular}

Distribusi kejadian BBLR diakibatkan ibu yang merokok berjumlah 3 kasus (5\%) dan untuk ibu yang tidak merokok berjumlah 59 kasus (95\%) (Tabel 5).
Tabel 5. Distribusi frekuensi kejadian BBLR berdasarkan kebiasaan merokok

\begin{tabular}{ccc}
\hline Kebiasaan merokok & Jumlah & \% \\
\hline Merokok & 3 & 5 \\
Tidak merokok & 59 & 95 \\
Total & 62 & 100 \\
\hline
\end{tabular}

Distribusi kejadian BBLR pada ibu yang mengonsumsi alkohol berjumlah 1 kasus (2\%) dan ibu yang tidak mengonsumsi alkohol berjumlah 61 kasus (98\%) (Tabel 6)

Tabel 6. Distribusi frekuensi kejadian BBLR berdasarkan alkohol

\begin{tabular}{ccc}
\hline Alkohol & Jumlah & \% \\
\hline $\begin{array}{c}\text { Mengonsumsi alkohol } \\
\text { Tidak mengonsumsi } \\
\text { alkohol }\end{array}$ & 61 & 98 \\
Total & 62 & 100 \\
\hline
\end{tabular}

Distribusi kejadian BBLR infeksi pada ibu mendapatkan Torch berjumlah 2 kasus (3\%), keputihan berjumlah 11 kasus (18\%), leukositosis berjumlah 1 kasus $(2 \%)$ dan yang tidak memiliki infeksi berjumlah 48 kasus (77\%) (Tabel 7).

Tabel 7. Distribusi frekuensi kejadian BBLR berdasarkan infeksi pada ibu

\begin{tabular}{ccc}
\hline Infeksi pada ibu & Jumlah & $\mathbf{\%}$ \\
\hline TORCH & 2 & 3 \\
Keputihan & 11 & 18 \\
Leukositosis & 1 & 2 \\
Tidak memilki infeksi & 48 & 77 \\
Total & 62 & 100 \\
\hline
\end{tabular}

Distribusi kejadian berat lahir rendah pada kehamilan ganda berjumlah 7 kasus (11\%) dan pada kehamilan tunggal atau yang tidak hamil ganda sebanyak 55 kasus (89\%) (Tabel 8)

Tabel 8. Distribusi frekuensi kejadian BBLR berdasarkan kehamilan ganda (Gemeli)

\begin{tabular}{ccc}
\hline Kehamilan ganda & Jumlah & \% \\
\hline Hamil ganda & 7 & 11 \\
Tidak hamil ganda & 55 & 89 \\
Total & 62 & 100 \\
\hline
\end{tabular}

Distribusi kejadian BBLR yang 
memiliki riwayat BBLR sebelumnya berjumlah 5 kasus (8\%) dan yang tidak memiliki riwayat BBLR sebelumnya berjumlah 57 kasus (92\%) (Tabel 9).

Tabel 9. Distribusi frekuensi kejadian BBLR berdasarkan riwayat BBLR sebelumnya

\begin{tabular}{ccc}
\hline $\begin{array}{c}\text { Riwayat BBLR } \\
\text { sebelumnya }\end{array}$ & Jumlah & $\%$ \\
\hline $\begin{array}{c}\text { Memiliki riwayat } \\
\text { Tidak memiliki } \\
\text { riwayat } \\
\text { Total }\end{array}$ & 57 & 82 \\
\hline
\end{tabular}

Distribusi komplikasi yang tersering ialah ibu yang tidak memiliki komplikasu sebanyak 50 kasus (81\%) diikuti oleh ketuban pecah dini sebanyak 8 kasus (13\%) dan hipertensi sebanyak 4 kasus (6\%) (Tabel 10).

Tabel 10. Distribusi frekuensi kejadian BBLR berdasarkan komplikasi

\begin{tabular}{ccc}
\hline Komplikasi & Jumlah & \% \\
\hline Ketuban pecah dini & 8 & 13 \\
Hipertensi & 4 & 6 \\
Tidak memiliki & 50 & 81 \\
komplikasi & & \\
Total & 62 & 100 \\
\hline
\end{tabular}

Distribusi kejadian BBLR diakibatkan kelahiran prematur sebanyak 34 kasus (55\%) dan kelahiran yang tidak prematur sebanyak 28 kasus (45\%) (Tabel 11).

Tabel 11. Distribusi frekuensi kejadian BBLR berdasarkan kelahiran prematur

\begin{tabular}{ccc}
\hline Kelahiran prematur & Jumlah & \% \\
\hline Prematur & 34 & 55 \\
Tidak prematur & 28 & 45 \\
Total & 62 & 100 \\
\hline
\end{tabular}

\footnotetext{
Distribusi kejadian BBLR yang diakibatkan kelainan bawaan memperlihatkan neonatus dnegan BBLR yang diakibatkan kelainan bawaan berjumlah 3 kasus (5\%) dan yang tidak memiliki kelainan bawaan berjumlah 59 kasus (95\%) (Tabel 12).
}

Tabel 12. Distribusi frekuensi kejadian BBLR berdasarkan kelainan bawaan

\begin{tabular}{ccc}
\hline Kelainan bawaan & Jumlah & \% \\
\hline $\begin{array}{c}\text { Memiliki kelainan } \\
\text { bawaan }\end{array}$ & 3 & 5 \\
$\begin{array}{c}\text { Tidak memiliki kelainan } \\
\text { bawaan } \\
\text { Total }\end{array}$ & 59 & 95 \\
\hline
\end{tabular}

Distribusi kejadian BBLR yang diakibatkan faktor risiko yang belum diketahui sejumlah 12 kasus (19\%) dan faktor risiko yang diketahui sejumlah 50 kasus (81\%) (Tabel 13).

Tabel 13. Distribusi frekuensi kejadian BBLR berdasarkan faktor risiko yang belum diketahui

\begin{tabular}{ccc}
\hline $\begin{array}{c}\text { Faktor yang belum } \\
\text { diketahui }\end{array}$ & Jumlah & $\mathbf{\%}$ \\
\hline Diketahui & 50 & 81 \\
Tidak diketahui & 12 & 19 \\
Total & 62 & 100 \\
\hline
\end{tabular}

\section{BAHASAN}

Berdasarkan tahun, neonatus yang lahir dengan BBLR pada tahun 2015 lebih banyak dibandingkan pada tahun 2016. karena untuk tahun 2016 hanya diambil data sampai bulan Juli.

Berdasarkan jenis kelamin, neonatus dengan BBLR berjenis kelamin laki-laki berjumlah lebih banyak dibanding dengan yang berjenis kelamin perempuan. Hal ini tidak sejalan dengan penelitian yang dilakukan oleh Pramono dan Putro ${ }^{10}$ yang melaporkan bahwa neonatus dengan BBLR yang berjenis kelamin perempuan $(5,4 \%)$ lebih banyak dibandingkan yang berjenis kelamin laki-laki $(4,1 \%)$. Sejauh ini belum diketahui referensi atau kasus yang menyatakan bahwa jenis kelamin bayi berpengaruh terhadap kelahiran BBLR. ${ }^{10}$

Berdasarkan usia ibu, angka kejadian terbanyak dari neonatus dengan BBLR pada ibu dengan kelompok usia 20- 35 tahun diikuti oleh kelompok usia $>35$ tahun dan $<20$ tahun. Hal ini didukung dengan penelitian yang dilakukan oleh Hasanah et al. ${ }^{11}$ yang mendapatkan kelompok usia tersering melahirkan neonatus dengan BBLR ialah kelompok usia 20-35 tahun 
$(54,3 \%)$ kemudian diikuti usia $>35$ tahun $(30,5 \%)$ dan $<20$ tahun $(15,2 \%)$.

Berdasarkan jumlah anak (paritas), angka kejadian BBLR terbanyak pada ibu yang baru mempunyai 1 orang anak sedangkan angka kejadian yang paling sedikit ialah ibu yang mempunyai 5 orang anak. Hal ini tidak sejalan dengan penelitian yang dilakukan oleh Sulistyorini dan Siswoyo ${ }^{12}$ yang mendapatkan angka kejadian terbanyak ialah ibu yang melahirkan 2 kali atau mempunyai 3 orang anak $(95,6 \%)$ dan angka kejadian yang paling sedikit pada ibu yang melahirkan lebih dari 4 kali $(4,4 \%)$.

Berdasarkan kebiasaan merokok, ibu yang merokok lebih sedikit daripada ibu yang tidak merokok. Hal ini didukung dengan penelitian yang dilakukan oleh Mahdalena et al. ${ }^{13}$ yang mendapatkan ibu yang tidak merokok cenderung lebih lebih banyak dibandingkan dengan ibu yang merokok aktif tetapi ibu yang berpeluang melahirkan bayi dengan BBLR ialah ibu yang terpapar dengan asap rokok dari suami, keluarga, atau lingkungan sekitar (perokok pasif).

Berdasarkan mengonsumsi alkohol, ibu yang tidak mengonsumsi alkohol lebih banyak daripada ibu yang mengonsumsi alkohol. Hal ini didukung dengan penelitian yang dilakukan oleh $\mathrm{Adi}^{14}$ yang mendapatkan ibu yang tidak mengonsumsi alkohol lebih banyak.

Berdasarkan infeksi pada ibu, infeksi yang paling tersering terjadi ialah keputihan. Ibu yang tidak mengalami infeksi lebih banyak dibandingkan ibu yang mengalami infeksi. Hal ini didukung dengan penelitian oleh $\mathrm{Adi}^{14}$ dengan hasil ibu yang tidak memiliki infeksi lebih banyak.

Berdasarkan hamil ganda, ibu yang tidak memiliki kehamilan ganda lebih banyak dibandingkan yang memiliki kehamilan ganda. Hal ini didukung dengan penelitian oleh Tjekyan ${ }^{15}$ yang mendapatkan kehamilan ganda merupakan faktor tersering pada BBLR karena pasokan darah untuk kehamilan ganda terbagi dua atau lebih untuk masing-masing janin sehingga pasokan nutrisi terbagi.

Berdasarkan riwayat BBLR sebelumnya, ibu yang tidak memiliki riwayat BBLR lebih banyak. Hal ini didukung dengan penelitian oleh $\mathrm{Adi}^{14}$ yang mendapatkan ibu yang tidak memiliki riyawat BBLR sebelumnya lebih banyak dibanding yang memiliki riwayat sebelumnya.

Berdasarkan komplikasi, ibu yang tidak memiliki komplikasi pada kehamilan lebih banyak. Hal ini didukung dengan penelitian oleh Puspita et al. ${ }^{16}$ dengan hasil yang serupa.

Berdasarkan kelahiran prematur, neonatus yang lahir dengan kelahiran prematur atau dismatur hampir sama jumlahnya. Hal ini didukung dengan penelitian oleh $\mathrm{Adi}^{14}$ yag melaporkan jumlah kasus BBLR yang diakibatkan kelahiran prematur atau dismatur hampr sama banyak tetapi menurut Nelson menyebutkan bahwa kejadian berat badan lahir rendah di negara berkembang, termasuk Indonesia, lebih banyak untuk kejadian dismatur dibandingkan prematur. Kemungkinan ini diakibatkan oleh jumlah sampel penelitian yang lebih sedikit akibat banyak dieksklusi, selain itu cakupan yang terbatas untuk ibu yang melahirka di RSUP Prof. R. D. Kandau Manado.

Berdasarkan kelainan bawaan, hal ini didukung dengan penelitian oleh $\mathrm{Adi}^{14}$ yang mendapatkan kelainan kongenital tidak mempunyai hubungan bermakna secara statistik dengan BBLR.

\section{SIMPULAN}

Berdasarkan hasil penelitian terhadap faktor risiko yang berhubungan dengan kejadian BBLR di Bagian Ilmu Kesehatan Anak RSUP. Prof Dr. R. D. Kandou Manado periode Januari 2015-Juli 2016 dapat disimpulkan bahwa faktor ibu merupakan yang tersering khususnya kelahiran prematuritas, diikuti oleh riwayat BBLR sebelumnya, hamil ganda, usia ibu, paritas, infeksi pada ibu, dan komplikasi pada kehamilan. 


\section{SARAN}

1. Perlu dilakukan anamesis lengkap tentang faktor-faktor risiko pada ibu yang melahirkan neonatus dengan berat badan lahir rendah.

2. Perlunya komunikasi, informasi, dan edukasi terhadap ibu untuk mengurangi terjadinya berat badan lahir rendah.

\section{DAFTAR PUSTAKA}

1. Depkes RI. Profil Kesehatan Indonesia. Jakarta: Departemen Kesehatan Republik Indonesia, 2011

2. Khatun S, Rahman M. Socio-economic determinant of low birth weight in Bangladesh: A multivariate approach. Bangladesh Med Res Counc Bul; 2008;34: 81-6.

3. WHO, UNICEF. Low birth weight country, regional ang global estimates. New York: WHO, 2004.

4. WHO. World Health Statistic. New York: World Health Organization, 2012.

5. Dinas Kesehatan. Riset kesehatan dasar. Jakarta: Badan Penelitian dan Pengembangan Kesehatan, Jakarta: Departemen Kesehatan Republik Indonesia, 2013.

6. Dinas Kesehatan. Narasi pofil kesehatan Indonesia Tahun 2014. Jakarta: Dinas Kesehatan Indonesia, 2014.

7. Pusat Statistik. Sulawesi Utara dalam angka. Manado: Badan Pusat Statistik Provinsi Sulawesi Utara, 2015.

8. Pinontoan VM, Tombokan SG. Hubungan umur dan paritas ibu dengan kejadian berat badan lahir rendah. Jurnal Ilmiah Bidan. 2015;3(1):20-5.

9. Rosmala N, Adhar A, Novilia R. Analisis faktor resiko kejadian berat badan lahir rendah di Rumah Sakit Umum Anutapura Palu. Palu: Fakultas Kedokteran dan Ilmu Kesehatan
Universitas Tadulako; 2016.

10. Pramono MS, Putro G. Risiko terjadinya berat badan lahir rendah menurut determinan sosial, ekonomi dan demografi di Indonesia. Buletin penelitian Sistem Kesehatan. 2009;12(2):127-32.

11. Hasanah N, Kurniawati T, Kurniati L. Faktor-faktor yang berhubungan dengan kejadian bayi berat lahir rendah (BBLR) di ruang BBRT RSUP Dr. Kariadi Semarang tahun 2010. Semarang: Akademi Kebidanan Abdi Husada Semarang; 2011.

12. Sulistyorini S, Siswoyo S. Analisis faktorfaktor yang mempengaruhi kejadian BBLR di puskesmas perkotaan Kabupaten Banjarnegara. Banjarnegara: Politeknik Banjarnegara; 2013.

13. Mahdalena, Ningsih ESP, Noor S. Pengaruh rokok terhadap berat badan bayi baru lahir di RSUD Banjarbaru. Jurnal Skala Kesehatan. 2014;5(2).

14. Mahayana SA, Chundreyetti E, Yulistini. Faktor risiko yang berpengaruh terhadap kejadian berat badan lahir rendah di RSUP Dr. Djamil Padang. Jurnal kesehatan Andalas. 2015;4(3):664-73.

15. Tjekyan RMS. Faktor risiko dan prognosis berat badan lahir rendah (BBLR) dan berat badan lahir sangat rendah (BBLSR) dan kejadian lahir mati di Kota Palembang tahun 2010. Majalah Kedokteran Sriwijaya. 2010;42(3):2925.

16. Zendrato DP, Rahayu, Hiswani. Hubungan faktor sosiodemografis dan faktor kehamilan dengan kejadian bayi berat lahir rendah (BBLR) di RSIA Sri Ratu Medan Tahun 2014 [Skripsi]. Medan: Fakultas Kesehatan Masyarakat USU; 2015. 
Jurnal e-Clinic (eCl), Volume 4, Nomor 2, Juli-Desember 2016 